\title{
Role of Endothelin-1/Endothelin-A Receptor-mediated Signaling Pathway in the Aortic Arch Patterning in Mice
}

\author{
Hiromi Yanagisawa, ${ }^{\ddagger}$ Robert E. Hammer, ${ }^{\star \ddagger}$ James A. Richardson, ${ }^{\S}$ S. Clay Williams, ${ }^{\star *}$ David E. Clouthier, ${ }^{\star \|}$ \\ and Masashi Yanagisawa*| \\ *Howard Hughes Medical Institute, ${ }^{\ddagger}$ Department of Biochemistry, ${ }^{\S}$ Department of Pathology, and $\|^{\|}$Department of Molecular Genetics, \\ University of Texas Southwestern Medical Center at Dallas, Dallas, Texas 75235-9050
}

\begin{abstract}
The intercellular signaling mediated by endothelins and their $\mathrm{G}$ protein-coupled receptors has recently been shown to be essential for the normal embryonic development of subsets of neural crest cell derivatives. Endothelin-1 (ET-1) is proteolytically generated from its inactive precursor by endothelin-converting enzyme-1 (ECE-1) and acts on the endothelin-A $\left(E T_{A}\right)$ receptor. Genetic disruption of this ET$1 / \mathrm{ECE}-1 / \mathrm{ET}_{\mathrm{A}}$ pathway results in defects in branchial archderived craniofacial tissues, as well as defects in cardiac outflow and great vessel structures, which are derived from cephalic (cardiac) neural crest. In this study, in situ hybridization of $E T_{A}{ }^{-1-}$ and $E C E-1^{-1-}$ embryos with a cardiac neural crest marker, cellular retinoic acid-binding protein-1, shows that the migration of neural crest cells from the neural tube to cardiac outflow tract is not affected in these embryos. Immunostaining of an endothelial marker, platelet endothelial cell adhesion molecule CD-31, shows that the initial formation of the branchial arch arteries is not disturbed in $E T_{A}^{-1-}$ or $E C E-1^{-1-}$ embryos. To visualize the subsequent patterning of arch vessels in detail, we generated $E T_{A}{ }^{-l-}$ or $E C E-1^{-l-}$ embryos that expressed an SM22 $\alpha$-lacZ marker transgene in arterial smooth muscle cells. Wholemount X-gal staining of these mutant embryos reveals that the abnormal regression and persistence of specific arch arteries results in disturbance of asymmetrical remodeling of the arch arteries. These defects include abnormal regression of arch arteries 4 and 6, enlargement of arch artery 3, and abnormal persistence of the bilateral ductus caroticus and right dorsal aorta. These abnormalities eventually lead to various types of great vessel malformations highly similar to those seen in neural crest-ablated chick embryos and human congenital cardiac defects. This study demonstrates that ET-1/ET $\mathrm{A}_{\mathrm{A}}-$ mediated signaling plays an essential role in a complex process of aortic arch patterning by affecting the postmigratory cardiac neural crest cell development. $(J$. Clin. Invest. 1998. 102:22-33.) Key words: cardiovascular malformation $\bullet$ branchial arch artery $\bullet$ cardiac neural crest $\bullet$ gene targeting $\bullet$ mouse
\end{abstract}

Address correspondence to Masashi Yanagisawa, Howard Hughes Medical Institute, University of Texas Southwestern Medical Center, 5323 Harry Hines Blvd., Room Y5.224, Dallas, TX 75235-9050. Phone: 214-648-5082; FAX: 214-648-5068; E-mail: afcsushi@aol.com

Received for publication 30 December 1997 and accepted in revised form 22 April 1998.

J. Clin. Invest.

(C) The American Society for Clinical Investigation, Inc. 0021-9738/98/07/0022/12 \$2.00

Volume 102, Number 1, July 1998, 22-33

http://www.jci.org

\section{Introduction}

Establishing the circulatory system requires the organized development of the heart and vessels. During embryogenesis, six pairs of branchial arch arteries appear in a rostral to caudal direction, and form the precursors of the great vessels and large arteries in the head and neck. Arch arteries arise from the aortic sac and terminate in the dorsal aorta, penetrating the corresponding branchial arches. The first pair of arch arteries is formed on approximately embryonic day $8.5(\mathrm{E} 8.5)^{1}$ in mice $(1,2)$. Arch arteries 1 and 2 regress and become capillaries in branchial arches 1 and 2 by E11.0, whereas arch arteries 3 and 4 continue to enlarge. Bilateral pulmonary arteries branch off from the proximal part of arch arteries 6 . All of the caudal arch arteries develop symmetrically until around E11.5. However, arch arteries undergo dramatic remodeling to correctly establish the embryonic circulatory system and to prepare for postnatal circulation. This remodeling process includes the asymmetrically programmed regression and persistence of specific arch arteries. For instance, right arch artery 4 reduces in relative size and leads to vertebral and subclavian arteries, whereas left arch artery 4 persists and forms a segment of the arch of aorta. Right arch artery 6 regresses and eventually disappears, whereas left arch artery 6 becomes the ductus arteriosus and supports the fetal circulation until parturition. Both arch arteries 3 remain to form bilateral common carotid arteries. This sequential remodeling of the arch arteries together with the regression of the right dorsal aorta results in a highly asymmetrical arterial system.

The molecular mechanisms of the arch artery remodeling and genetic determinant involved in this process are yet to be fully understood. The intimate involvement of cardiac neural crest cells in this process have been suggested by the phenotype resulting from the cardiac neural crest ablation in chick embryos, where various types of great vessel abnormalities and septation defects of the outflow tract develop (3). Cardiac neural crest derives from the dorsal aspect of the neural tube at the level between otic placode and somite 3. Cardiac neural crest cells undergo epithelial-mesenchymal transformation and migrate through branchial arches $3,4,6$, and the circumpharyngeal region, eventually to the outflow tract of the heart (4). Cardiac neural crest cells entering the heart can be detected using genetic markers such as cellular retinoic acidbinding protein-1 (CRABP-1) and pax3 in E10.5 mice (5). It is shown in the quail-to-chick chimeras that the mesenchyme of

1. Abbreviations used in this paper: CRABP-1, cellular retinoic acidbinding protein-1; E, embryonic day; ECE-1, endothelin-converting enzyme-1; ET, endothelin; $\mathrm{ET}_{\mathrm{A}}$, endothelin receptor type-A; DORV, double outlet right ventricle; PECAM, platelet endothelial cell adhesion molecule; PTA, persistent truncus arteriosus; RT, room temperature. 
branchial arch arteries is entirely made from neural crest cells (6). Contribution of the cardiac neural crest cells in the formation of the aorticopulmonary septum is also demonstrated in neural crest-ablated chick embryos (7). Cardiac neural crestablated chick embryos seem to develop a wide spectrum of malformations depending on the amount and location of the neural crest taken from the embryos, e.g., ablating a large amount results in persistent truncus arteriosus (PTA), whereas ablating small amounts results in dextroposed aorta (8). Certain types of human congenital cardiovascular malformations, including the CATCH 22 syndrome $(9,10)$, type B interruption of the aortic arch (11), PTA (12), and double outlet right ventricle (DORV) (13), strongly resemble defects seen in neural crest-ablated chick embryos. However, the precise cellular and molecular mechanism by which the neural crest is involved in cardiac development is not completely understood.

We have recently shown that mice deficient in either the endothelin receptor type-A $\left(E T_{A}\right)$ gene or the endothelin-converting enzyme-1 (ECE-1) gene develop defects in a subset of cephalic and cardiac neural crest derivatives $(14,15)$. Endothelins are a family of small peptides comprised of three structurally related isoforms called ET-1, ET-2, and ET-3 $(16,17)$. ECE-1 catalyzes the proteolytic activation of biologically inactive intermediates big ET-1 and big ET-3 to biologically active ET-1 and ET-3, respectively $(14,18) . \mathrm{ET}_{\mathrm{A}}$ is one of the two known endothelin receptors that belong to the seven membrane-spanning $\mathrm{G}$ protein-coupled receptor family. It binds ET-1 and ET-2, but not ET-3 at physiological concentrations (19). $\mathrm{ET}_{\mathrm{A}}$ receptor-deficient mice show defects in craniofacial structures, great vessels, and cardiac outflow tract. $E C E-1$ null mice exhibit a virtually identical phenotype to $E T-1^{-1-}$ (20) and $E T_{A}{ }^{-1-}$ (15) embryos in these tissues due to the absence of biologically active ET-1. In addition, ECE-1-deficient mice lack enteric neurons and epidermal/choroidal melanocytes, reproducing the phenotype of $E T-3^{-/-}$(21) or $E T_{B}{ }^{-1-}$ mice (22).

The most common great vessel malformations in $E C E-1^{-1-}$ and $E T_{A}{ }^{-1-}$ mice are interruption of the aortic arch between the left common carotid artery and left subclavian artery (type $\mathrm{B}$ interruption of the aortic arch). The second most common defect is an absence of the right subclavian artery. Among outflow tract abnormalities, perimembranous interventricular septal defect is observed in almost all the $E C E-1^{-1-}$ and $E T_{A}{ }^{-1-}$ embryos. We also observe overriding of the aorta, DORV, and, in a small number of cases, PTA. These cardiac phenotypes highly resemble those of mice and chick embryos that have defects in cardiac neural crest development $(3,23)$. In this study, we further investigated the role of ET-1/ECE-1/ET $\mathrm{A}_{\mathrm{A}}-$ medi- $^{-}$ ated signaling in the cardiac neural crest development. To visualize the development of the branchial arch vessels, we crossed $E T_{A}{ }^{-1-}$ and $E C E-1^{-1-}$ mice with $S M 22 \alpha$-lacZ reporter transgenic mice (24). The lac $Z$ gene, driven by a smooth muscle-specific $S M 22 \alpha$ promoter, was expressed in arterial smooth muscle cells in these transgenic mice. Therefore, we were able to examine the arch artery patterning by wholemount X-gal staining in mutant embryos. We show that abnormal regression and persistence of the branchial arch arteries in $E C E-1^{-1-}$ and $E T_{A}^{-1-}$ embryos leads to the observed great vessel malformations.

\section{Methods}

Mice. All animal experimental procedures were reviewed and approved by the Institutional Animal Care and Research Advisory
Committee of the University of Texas Southwestern Medical Center. Mice deficient for $E C E-1$ and $E T_{A}$ were generated by homologous recombination as described $(14,15)$, and maintained on a C57BL6 $\times$ $129 / \mathrm{SvEv}$ hybrid genetic background. SM22 $\alpha$-lacZ transgenic mice harboring the pSM2737/1093-lacZ transgene were generated and maintained on a C57BL6 $\times$ CBA hybrid background as previously described (24). Mice were housed in a conventional animal colony and maintained on a 14-h light/10-h dark cycle.

Generation and harvesting of embryos. Male mice homozygous for $S M 22 \alpha$-lac $Z$ transgene were mated to heterozygous $E C E-1$ or $E T_{A}$ females to subsequently generate male offspring that were heterozygous for $E C E-1$ or $E T_{A}$ and homozygous for transgene. They were then mated to heterozygous $E C E-1$ or $E T_{A}$ females to obtain embryos that were positive for the transgene and wild type, heterozygous or homozygous for the targeted $E C E-1$ or $E T_{A}$ allele. The morning that the vaginal plug was found was counted as E0.5. Pregnant females were killed between $\mathrm{E} 9.0-13.5$ by inhalation of $\mathrm{CO}_{2}$, and embryos were harvested from the uterus. The staging of the embryos was determined by the number of somites as well as the external features of embryos as previously described (2). The yolk sac was kept for genomic DNA preparation.

Genotyping. Genomic DNA was prepared from tail biopsies at postnatal day 21 or from embryo yolk sac, and subjected to PCR and/ or Southern blot analysis. Oligonucleotide primers used for the detection of wild-type ECE-1 allele were: upstream, 5'-ATGACGCCGCCCATGGTGAAC-3' and downstream, 5' -TGGTTGGGCTAAGACATAAC- $3^{\prime}$. Primers for the detection of $n e o^{r}$ allele were: upstream primer, 5'-TATTCGGCTATGACTGGGCACAACAG-3' and downstream primer, 5'-TTCCACCATGATATTCGGCAAGCAGG-3'. The reaction was cycled $30 \times\left(30 \mathrm{~s}\right.$ at $94^{\circ} \mathrm{C}, 1 \mathrm{~min}$ at $60^{\circ} \mathrm{C}, 3 \mathrm{~min}$ at $72^{\circ} \mathrm{C}$ ), which amplified a 128-bp of the ECE-1 gene and a 500-bp of the $n e o^{r}$ gene, respectively. Primers used for the detection of wildtype $E T_{A}$ allele were; upstream primer, 5'-TCTGGTCAGTTCCTGCTTTCCTCCTGG-3' and downstream primer, 5'-CGATGTAATCCATTAGCAGCAAGAAGCTGG-3'. The reaction was cycled $30 \times\left(30 \mathrm{~s}\right.$ at $93^{\circ} \mathrm{C}, 30 \mathrm{~s}$ at $60^{\circ} \mathrm{C}, 3 \mathrm{~min}$ at $\left.68^{\circ} \mathrm{C}\right)$ and amplified a 800 -bp band. For the detection of mutated $E T_{A}$ allele, upstream primer, 5'-TCGCCTTCTTGACGAGTTCTTCTGAG-3' and downstream primer, $5^{\prime}$-TGGGAATGGACCTGAGTCCTCTGC-3' were used. The reaction was cycled $35 \times\left(1 \mathrm{~min}\right.$ at $94^{\circ} \mathrm{C}, 2 \mathrm{~min}$ at $55^{\circ} \mathrm{C}, 3 \mathrm{~min}$ at $72^{\circ} \mathrm{C}$ ), which amplified a 450 -bp band. Genotyping of $S M 22 \alpha$-lacZ transgenic mice was performed as previously described (25). For Southern blot analysis, $10 \mu \mathrm{g}$ of genomic DNA was digested with ApaI and BamHI for the analysis of the ECE-1 allele and with XbaI for the $E T_{A}$ allele, respectively. Membranes were hybridized with a $5^{\prime}$ external probe for $E C E-1$ and with a $3^{\prime}$ external probe for $E T_{A}$ as previously described (15).

$\beta$-Galactosidase staining and histology. Embryos were rinsed with PBS and fixed in $4 \%$ paraformaldehyde/PBS at $4^{\circ} \mathrm{C}$ for $1 \mathrm{~h}$. After rinsing with lacZ rinse buffer $(0.2 \mathrm{M}$ sodium phosphate, $\mathrm{pH} 7.3,2$ $\mathrm{mM} \mathrm{MgCl} 2,0.02 \%$ NP- $40,0.01 \%$ sodium deoxycholate), embryos were incubated in lacZ rinse buffer containing $5 \mathrm{mM} \mathrm{K}_{4} \mathrm{Fe}(\mathrm{CN})_{6}, 5 \mathrm{mM}$ $\mathrm{K}_{3} \mathrm{Fe}(\mathrm{CN})_{6}$ and $1 \mathrm{mg} / \mathrm{ml}$ 5-bromo-4-chloro-3-indolyl- $\beta$-D-galactopyranoside (X-gal) at $37^{\circ} \mathrm{C}$ for $24-48 \mathrm{~h}$. Embryos were postfixed in $10 \%$ formalin at $4^{\circ} \mathrm{C}$ overnight, dehydrated through graded steps into $100 \%$ methanol and cleared in a solution of benzyl benzoate:benzyl alcohol (1:1). For histology, stained embryos were dehydrated in ethanol and cleared in cedar oil (Polyscience, Warrington, PA). Then they were embedded in paraffin and sectioned into $4-\mu \mathrm{m}$ thickness and counterstained with eosin.

Wholemount immunohistochemistry. Harvested embryos were rinsed with cold PBS and fixed in $4 \%$ paraformaldehyde at $4^{\circ} \mathrm{C}$ overnight. After rinsing and dehydration through a graded series of methanol at room temperature (RT), embryos were bleached in $5 \% \mathrm{H}_{2} \mathrm{O}_{2} /$ methanol for $5 \mathrm{~h}$, followed by rehydration and blocking in PBSMT (3\% skim milk, $0.1 \%$ Triton X-100, PBS) at RT twice for $1 \mathrm{~h}$. Embryos were incubated in $10 \mu \mathrm{g} / \mathrm{ml}$ purified antimouse CD31 (MEC13.3, antimouse platelet-derived endothelial adhesion molecule, PharMingen, San Diego, CA) in PBSMT at $4^{\circ} \mathrm{C}$ overnight, 
washed with PBSMT at $4^{\circ} \mathrm{C}$, and incubated with 1:100 dilution of horseradish peroxidase-conjugated goat anti-rat $\operatorname{IgG}(\mathrm{H}+\mathrm{L})$ (Kirkegaad and Perry Laboratories Inc., Gaithersburg, MD) in PBSMT at $4^{\circ} \mathrm{C}$ overnight. Embryos were again washed in PBSMT at $4{ }^{\circ} \mathrm{C}$ and rinsed in PBST $(0.2 \%$ BSA, $0.1 \%$ Triton X-100, PBS) at RT for 20 $\mathrm{min}$. For signal detection, embryos were incubated in $0.3 \mathrm{mg} / \mathrm{ml} \mathrm{di}$ aminobenzidine (Sigma Chemical Co., St. Louis, $\mathrm{MO}$ ), $0.5 \% \mathrm{NiCl}_{2}$ in PBT for $20 \mathrm{~min}$ and $\mathrm{H}_{2} \mathrm{O}_{2}$ was added to the final concentration of $0.03 \%$ and incubated for $10 \mathrm{~min}$. The staining reaction was terminated by rinsing the embryos in PBT. Stained embryos were postfixed in $4 \%$ paraformaldehyde/PBS at $4^{\circ} \mathrm{C}$ overnight and transferred to $50 \%$ glycerol/PBS, and then $70 \%$ glycerol/PBS.

Wholemount in situ hybridization. To generate the CRABP-1 probe, a 755-bp EcoRI fragment from pGmCRAPB I (26) was subcloned into a Bluescript vector (Stratagene, La Jolla, CA), and a single-stranded RNA probe was transcribed and labeled with digoxigenin-11-UTP (Boehringer Mannheim Biochemicals, Indianapolis, IN) using T7 RNA polymerase (antisense) and T3 RNA polymerase (sense). Embryos were fixed in $4 \%$ paraformaldehyde/diethyl pyrocarbonate-treated saline at $4^{\circ} \mathrm{C}$ overnight. After rinsing in PBT (0.1\% Tween 20, PBS), embryos were dehydrated in graded methanols and bleached in $6 \% \mathrm{H}_{2} \mathrm{O}_{2} /$ methanol at RT for $5 \mathrm{~h}$, rinsed, and rehydrated in PBT. Wholemount hybridization was performed as previously described (27). For signal detection, embryos were incubated with alkaline phosphatase-conjugated antidigoxigenin antibody (Boehringer Mannheim), and stained with nitroblue tetrazolium chloride and 5-bromo-4 chloro-3-indolyl-phosphate for $45 \mathrm{~min}$ at RT. Color reaction was terminated by washing embryos with PBT.

Sectional in situ hybridization. Sectional in situ hybridizations for $E T-1, E C E-1$, and $E T_{A}$ mRNA were performed as previously described (28), except that riboprobes were labeled with ${ }^{33} \mathrm{P}-\mathrm{UTP}(>1,000$ $\mathrm{Ci} / \mathrm{mmol}$; Amersham, Arlington Heights, IL) using the Maxiscript in vitro translation kit (Ambion, Inc., Austin, TX.). For RNA probes, a 380-bp SacI-HindIII fragment of the mouse ET-1 cDNA, a 350-bp EcoRV-BamHI fragment of the mouse $E T_{A}$ cDNA, and a 350-bp EcoRI fragment of the mouse ECE- 1 cDNA were transcribed in both sense and antisense directions, as previously described $(14,15)$.

\section{Results}

Expression of ET-1, ECE-1, and ET $T_{A}$ RNAs in branchial arch arteries. In situ hybridization analysis of E9.5, wild-type mouse embryos with $E T-1, E T_{A}$, and $E C E-1$ riboprobes showed the complementary expression patterns of $E T_{A}$ and ET-1 mRNA in migratory/postmigratory neural crest cells and their juxtaposing epithelial cells in branchial arches, respectively $(14,15)$. To examine the expression pattern of endothelin-related molecules in arch artery development, we performed in situ hybridization analysis using frontal sections of E10.25 embryos. Overall expression of ET-1 mRNA in the embryos was less abundant compared to $E T_{A}$ or $E C E-1$ mRNA. ET-1 mRNA was detected in the endothelium of arch arteries 2, 3, and bilateral dorsal aorta (Fig. 1, $A$ and $E$ ). $E T_{A}$ mRNA was abundantly expressed in the mesenchyme surrounding arch arteries 2 and 3 (Fig. $1 F, *$ ), as well as the mesenchyme of the head and the body (Fig. 1, $B$ and $F$ ). The endothelium of the arch arteries was negative for the $E T_{A}$ mRNA expression. ECE-1 mRNA was expressed in both the endothelium of arteries and the mesenchyme surrounding arch arteries 2 and 3, although the intensity of the expression was weaker than that of $E T_{A}$ mRNA (Fig. 1, $C$ and $G$; * in $G$ ). These findings are consistent with the previous observations in E9.5 embryos. There was no difference in the expression pattern of $E T-1, E T_{A}$, and $E C E-1$ mRNA between the right and left sides of the arch arteries.
Cardiac neural crest migration is not affected in ECE-1 or $E T_{A}$ null embryos. To examine whether migration of cardiac neural crest cells is affected in $E T_{A}{ }^{-1-}$ or $E C E-1^{-/-}$embryos, we performed wholemount in situ hybridization analysis using CRABP-1, a marker for cardiac neural crest cells. In E10.5 wild-type embryos, a stream of CRABP-1-positive cells was detected from the occipital neural tube to branchial arches 3,4 , and 6, as well as to the circumpharyngeal region (Fig. $2 \mathrm{~A}$, arrow). This staining pattern was compatible with that previously reported for migratory cardiac neural crest cells (5). In $E T_{A}{ }^{-1-}$ embryos, CRABP-1-positive cardiac neural crest cells migrated to the cardiac tissues in a manner similar to that of wild-type embryos (Fig. 2 B). Intensity of the CRABP-1 staining was similar between wild-type and mutant embryos, indicating that the defects in $E T_{A}{ }^{-/-}$embryos were not the result of a significant reduction in numbers of migratory neural crest cells. The CRABP-1 staining in ECE-1 $1^{-1-}$ embryos was also identical to that of wild-type and $E T_{A}{ }^{-1-}$ embryos (data not shown). These results indicate that the initial migration of the cardiac neural crest cells was not detectably affected in the absence of ET-1-mediated signaling.

Formation of the anterior arch arteries is not affected in $E C E-1$ or $E T_{A}$ null embryos. Because $E C E-1$ and $E T_{A}$ mutant embryos develop various defects in first and second branchial arch-derived tissues, we examined whether arch arteries 1 and 2 were also affected in $E C E-1^{-1-}$ or $E T_{A}^{-1-}$ embryos. To examine early vessel formation, we performed wholemount antiplatelet endothelial cell adhesion molecule CD-31-(PECAM) immunostaining in E9.5 mutant embryos. The endothelial cellspecific expression of PECAM highlights the endothelial lining of the aortic arches and other large arteries, thus enabling us to examine the gross anatomy of the vessels (29). In wildtype embryos, arch arteries 1 and 2 were well formed and drained into the dorsal aorta (Fig. $3 A, n=14$ ). The endothelial staining of the dorsal aorta and cardinal veins as well as endocardium of the heart and somites were detected. In $E T_{A}{ }^{-1-}$ (Fig. $3 \mathrm{~B}$ ) and $E C E-1^{-1-}$ (not shown) embryos, arch arteries 1 and 2 developed normally and drained into dorsal aorta. There was no aberrant branching or interruption of the dorsal aorta. Abnormal regression of aortic arches 1 and 2 was not found in any of the $E T_{A}^{-1-}(n=3)$ and $E C E-1^{-1-}(n=7)$ embryos examined. There were no differences in the structure of dorsal aorta and branchial arteries between wild-type, $E T_{A}{ }^{-1-}$, and $E C E-1^{-1-}$ embryos. These results indicate that initial formation of the branchial arch arteries is not affected in $E T_{A}{ }^{-1-}$ and ECE-1 $1^{-1-}$ embryos.

$S M 22 \alpha$-lacZ expression is not altered in ECE-1 or ET $T_{A}$ null embryos. We have previously shown that the cardiovascular defects observed in E18.5 ECE-1 ${ }^{-1-}$ or $E T_{A}{ }^{-1-}$ embryos were indistinguishable from each other, and resulted from the absence of ET-1/ET $\mathrm{A}_{\mathrm{A}}$-mediated signaling $(14,15)$. To investigate how and when the aortic arch abnormalities develop in ECE$1^{-/-}$or $E T_{A}^{-/-}$embryos, we generated embryos positive for a $S M 22 \alpha$-lacZ marker transgene and wild type, heterozygous or homozygous for the disrupted $E C E-1$ or $E T_{A}$ allele. SM22 $\alpha$ is a putative calcium-binding protein expressed in all myogenic lineages during mouse embryogenesis, and later restricted to smooth muscle cells (30). The promoter region of the $S M 22 \alpha$ gene that was used to direct transgene expression in these embryos showed a similar expression pattern to that of the endogenous molecule, except that it was detected only in arterial smooth muscle cells, the heart, and somites (24). The trans- 
gene starts to express in the primitive heart tube at E8.75, and in the outflow tract and dorsal aorta at E9.0. The expression in the developing branchial arch arteries and other arteries increases after E11.5, which coincides with the start of asymmetrical remodeling of paired arch arteries in mouse embryos. Taking advantage of this marker transgene, we analyzed the development of arch vessels by wholemount X-gal staining in $E C E-1^{-1-} ; S M 22 \alpha$-lacZ and $E T_{A}^{-1-}$; and $S M 22 \alpha$-lacZ embryos, and compared them with wild-type or heterozygous embryos. First, we examined whether the expression of this transgene was maintained in E11.5 ECE-1 ${ }^{-1-}$ or $E T_{A}{ }^{-1-}$ embryos. In wild-type embryos, lacZ staining was detected in dorsal aorta, somites, and the heart as well as large arteries including branchial arch arteries, carotid artery, basilar artery, and umbilical artery (Fig. $4 A$, left). The transgene expression was also detected in $E C E-1^{-1-}$ (Fig. $4 \mathrm{~A}$, right) or $E T_{A}^{-1-}$ (not shown) embryos in a manner similar to wild-type embryos. These results suggest that ET-1/ET $\mathrm{A}_{\mathrm{A}}$-mediated signaling does not affect the expression of the $S M 22 \alpha$-lac $Z$ transgene.
An intricate sequence of regression, persistence, and remodeling of arch arteries is affected in ECE-1 or ET $T_{A}$ null embryos. The first abnormality in branchial arch arteries was observed in E11.5 mutant embryos. In wild-type embryos, the right and left arch arteries 3, 4, and 6 arose from aortic sac and extended dorsolaterally to join dorsal aorta (Fig. $4 \mathrm{~B}$ ). At this stage, a symmetrical pattern of the arch arteries was maintained. In contrast, $75 \%$ of $E C E-1^{-1-}$ embryos and $50 \%$ of $E T_{A}{ }^{-1-}$ embryos showed enlargement of arch artery 3 and relative narrowing of arch artery 4 and 6 , both of which occurred more frequently on the right side (Fig. $4 C$; Table I). Staining in pulmonary arteries was detectable by this stage both in normal and mutant embryos.

By E12.0, asymmetry was seen in the normal arch artery development. Right arch artery 6 started to narrow from its proximal part (Fig. $5 \mathrm{~A}$, arrow). The left ductus caroticus also started narrowing (Fig. $5 \mathrm{~B}$ ). At this time, arch arteries 1 and 2 had regressed. In histological sections, arch artery 6 was clearly smaller in the right side compared to the left side (Fig. $5 C$ ). In
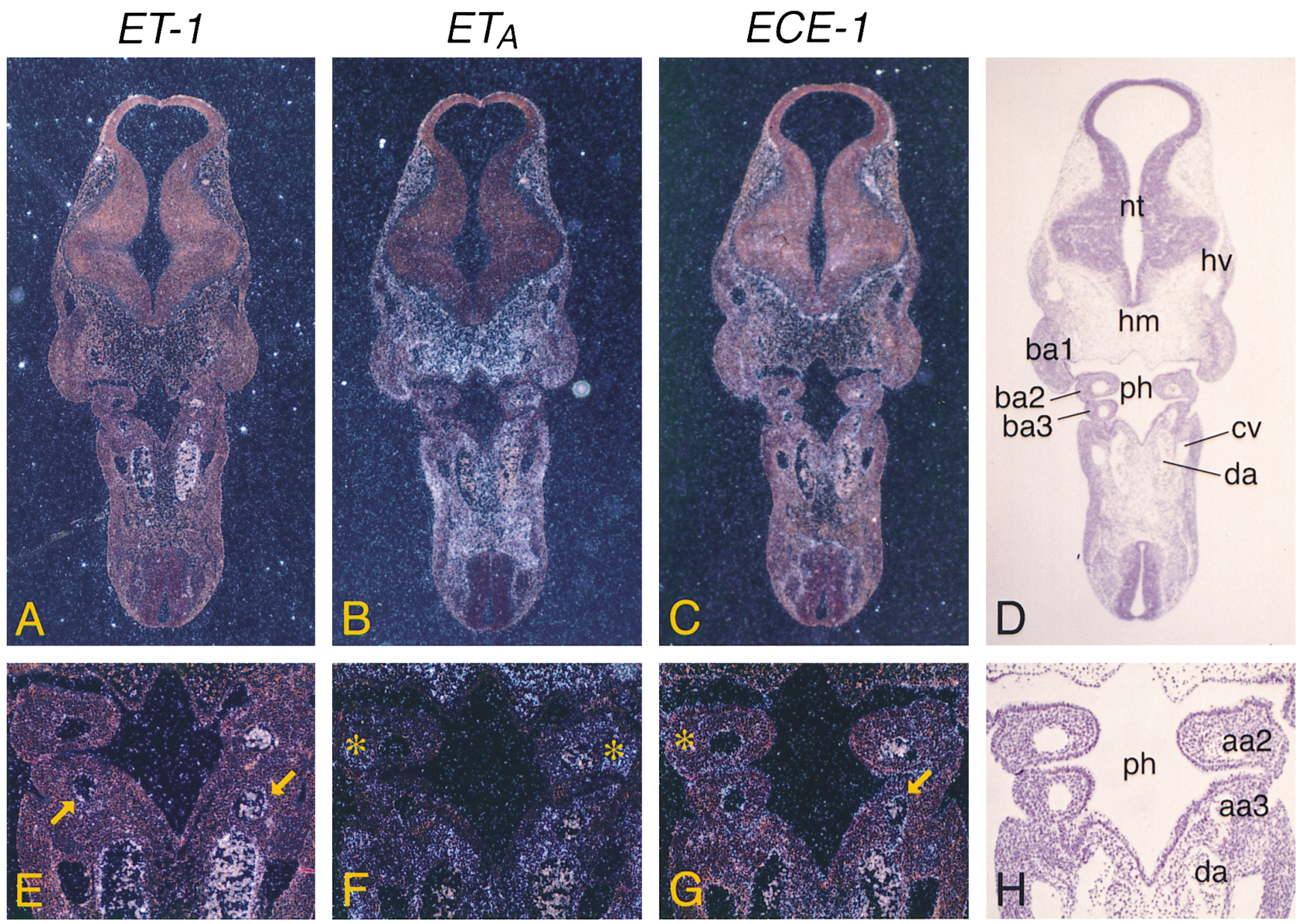

Figure 1. Expression of $E T-1$ ( $A$ and $E), E T_{A}(B$ and $F)$, and $E C E-1$ ( $C$ and $\left.G\right)$ mRNA in frontal sections of E10.25 wild-type mouse embryos. $E-H$ are enlargements of the branchial arch arteries shown in $A-D$, respectively. Corresponding bright fields are shown in $D$ and $H$. $(A$ and $E)$ ET-1 mRNA expression is detected in the endothelium of arch arteries 2 (aa2) and 3 (aa3, arrows), and bilateral dorsal aorta (da). Head mesenchyme $(\mathrm{hm})$ is negative for the expression of $E T-1 \mathrm{mRNA}$. ( $B$ and $F) E T_{A}$ mRNA is abundantly expressed in the mesenchyme of branchial arches 1 (ba1), branchial arches $2(b a 2)$, and branchial arches $3(b a 3)$ as well as body mesenchyme $(B)$. Note the marked expression of $E T_{A}$ mRNA in the mesenchyme surrounding arch arteries 2 and $3(*)$. The endothelium of the arch arteries is negative. $(C$ and $G) E C E-1 \mathrm{mRNA}$ is expressed in the head mesenchyme adjacent to the neuroepithelium and the mesenchyme of branchial arches and arch arteries $(C)$. Note that both endothelium and mesenchyme surrounding arch arteries 2 and 3 express $E C E-1$ mRNA $(G)$. $c v$, cardinal vein; $h v$, head vein; $h t$, neural tube; $p h$, pharynx. 
mutant embryos, right arch artery 3 was markedly enlarged, and large numbers of $E C E-1^{-1-}$ and $E T_{A}{ }^{-1-}$ embryos showed regression of right arch artery 4 (Fig. $5 E$, Table I). The diameter of right arch artery 4 was reduced and the level of X-gal staining was obviously decreased. Occasionally, a persistent aortic arch 2 was seen in mutant embryos (Fig. $5 F$ ). Regression of left arch artery 4 was also observed in $E C E-1^{-1-}$ and $E T_{A}{ }^{-1-}$ embryos, but was less frequently seen compared to the right arch artery 4 . In mutant embryos, the regressed arch artery 4 manifested as a remnant lumen on histological sections (Fig. 5 G, arrow).

In E12.5 embryos, arch arteries 3 extended cranially in wild-type embryos. The crown-rump length of embryos rapidly increase and arch arteries 3 grow toward the head. Both right and left ductus caroticus narrowed significantly, and right aortic arch 4 became the proximal part of the future subclavian artery (Fig. $5 \mathrm{D}$ ). Right and left external carotid arteries branched off from arch artery 3 and extended in a rostral direction. At this stage, right arch artery 6 was regressed in normal embryos (Fig. 5 D, arrow). Septation of the outflow tract was also noticeable in normal embryos. In contrast, abnormal regression of right arch artery 4 was observed in $85 \%$ of $E C E$ $1^{-1-}$ embryos and $67 \%$ of $E T_{A}^{-1-}$ embryos between E12.0E12.5 (Fig. $5 \mathrm{H}$ ). Arch arteries 3 became dominant vessels bilaterally, accepting the blood from the outflow tract. However, their overall growth toward the cranial direction was delayed. Absence of branching of the external carotid arteries from arch artery 3 was seen in both mutants (Fig. 5 H, arrowhead). Although some of the mutant embryos showed normal regression (Fig. $5 \mathrm{H}$, arrow), approximately half showed persistent right arch artery 6 . In addition, both right and left ductus caroticus remained (Fig. $5 \mathrm{H},{ }^{*}$ ) as did the right dorsal aorta.

At E13.0, the ascending part of the aortic arch and the aortic sac-derived proximal part of the brachiocephalic trunk continued to develop rostorally in wild-type embryos (Fig. 6 A).


Figure 2. Wholemount in situ hybridization analysis of a representative E10.5 wild-type $(A)$ and $E T_{A}^{-1-}(B)$ embryos with CRABP-1 riboprobe. In both wild-type and mutant embryos, the intense expression is detected in the dorsal neural tube, craniofacial region, and hindlimb. A stream of neural crest cells (arrow) is migrating through circumpharyngeal regions in both wild-type and mutant embryos. 1 , branchial arch $1 ; 2$, branchial arch $2 ; h$, heart; $h l$, hindlimb; ot, otic vesicle.
Left arch artery 4 developed and formed the arch of the aorta (Fig. $6 \mathrm{~B}$ ). The left subclavian artery, branching from the left dorsal aorta, remained lower than the left arch artery 6 (ductus arteriosus). Connection of the right dorsal aorta to the abdominal dorsal aorta was clearly narrowed (Fig. 6, $A$ and $C$, arrows), and the blood flow mainly passed through the left dorsal aorta, forming an asymmetrical arterial system. In mutant embryos, those whose right arch artery 4 had regressed showed persistent right arch artery 6 (Fig. $6 \mathrm{D}$ ), and connection of the right dorsal aorta to the abdominal dorsal aorta persisted (Fig. $6 \mathrm{D}$, arrow). Some of the mutant embryos showed extra branches from the ascending aorta, presumably either persistent aortic arch 2 or abnormal branching of the external carotid arteries (Fig. $6 E$, *). Only in $E C E-1^{-1-}$ embryos was right-sided dorsal aorta observed (Fig. $6 F$ ): left arch artery 4 (already disappeared), left arch artery 6 (arrow), left dorsal aorta (double arrows), and right arch artery 4 regressed (obstructed from the view). Right arch artery 6 and right dorsal aorta abnormally persisted and formed the major outflow from the heart (see Fig. $8 F$ ). Although persisted right dorsal aorta was observed in many $E T_{A}^{-1-}$ embryos, complete regression of the left dorsal aorta did not occur in these embryos. Thus, $E T_{A}{ }^{-1-}$ embryos did not develop right-sided dorsal aorta.

E13.5 wild-type embryos and all of the branchial arch arteries and major vessels had completed the remodeling process (Fig. 7, $A$ and $E$; Fig. $8 A$ ). In mutant embryos, abnormal vascular remodeling had led to various types of congenital great vessel malformations. Fig. 7, $B$ and $F$ show the phenotype resulting from abnormal regression of the right arch artery 4 (illustrated in Fig. $8 \mathrm{~B}$ ). Although the left side of the aortic system developed normally, blood flow entering brachiocephalic trunk went into the right common carotid artery (Fig. $7 \mathrm{~B}, 3$, aortic arch 3 derivative) to the right ductus caroticus and to the right subclavian artery. This pattern was recognized as the absence of the right subclavian artery (or cervical origin of the right subclavian artery) upon dissection of term embryos (14,



Figure 3. Wholemount anti-PECAM immunostaining of a representative E9.5 wild-type $(A)$ and $E T_{A}^{-1-}(B)$ embryos. The endothelium of branchial arch artery $1(1)$ and arch artery $2(2)$ as well as the heart $(h)$, dorsal aorta $(\mathrm{da})$, and somites $(\mathrm{sm})$ are stained in both wild-type and mutant embryos. 


\section{E11.5}
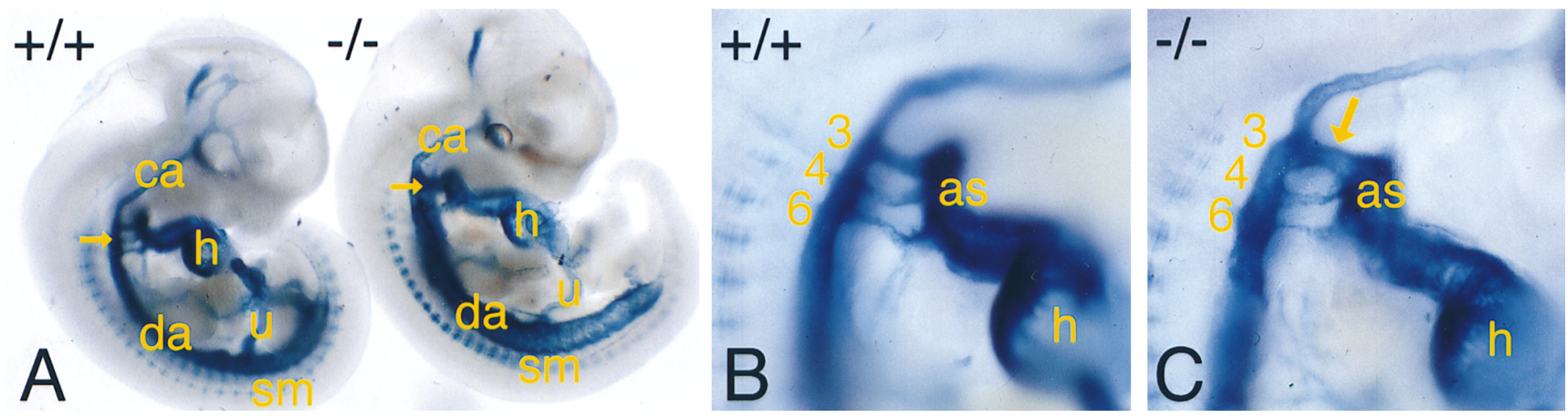

Figure 4. Wholemount X-gal staining of $E C E-1^{+/+} ; S M 22 \alpha-l a c Z$, and $E C E-1^{-1-}$; and $S M 22 \alpha$-lacZ embryos at E11.5. Genotype is indicated in each panel. $(A) \mathrm{X}$-gal staining visualizing dorsal aorta $(d a)$, heart $(h)$, branchial arch arteries (arrow), and major arterial vessels both in wild-type and mutant embryo. (B) Arch artery 3 (3), arch artery 4 (4), and arch artery 6 (6) arise from aortic sac (as) and terminate in dorsal aorta. (C) Arch artery 3 shows abnormal enlargement (arrow) compared to wild-type embryo. ca, carotid artery; $d a$, dorsal aorta; $u$, umbilical artery; sm, somites.

15). In some mutant embryos that showed abnormal regression of right arch artery 4 and normal regression of the right ductus caroticus, the right dorsal aorta persisted (not shown). This pattern illustrates the absence of the right subclavian artery (or dorsal aorta origin of the right subclavian artery; Fig. 8 $C)$. Fig. 7, $C$ and $G$ shows the double aortic arch resulting from abnormal regression of the right and left arch arteries 4 (Fig. 8 $D)$. Blood from the outflow tract entered the common carotid arteries (Fig. $7 C, 3$ ) and ran into the dorsal aorta via the ductus caroticus on both sides. Fig. 7, $D$ and $H$ are the other form of double aortic arch resulting from the abnormal regression of left arch artery 6 (ductus arteriosus). In these cases, blood from the outflow tract entered the right and left branchial arches 4 and right arch artery 6 , and joined the dorsal aorta from both sides (Fig. $8 \mathrm{E}$ ). However, right arch artery 4 and 6 was dominant over left arch artery 4.

Table I. Observed Frequency (\%) of Abnormalities in Branchial Arch Artery Development

\begin{tabular}{|c|c|c|c|c|c|c|c|}
\hline \multirow[b]{2}{*}{ Artery } & \multirow[b]{2}{*}{ Abnormality $y^{\ddagger}$} & \multicolumn{2}{|c|}{ E11.5 } & \multicolumn{2}{|c|}{ E12.0-12.5 } & \multicolumn{2}{|c|}{ E13.0-13.5 } \\
\hline & & $\begin{array}{c}E C E-1^{-/-} \\
(n=8)\end{array}$ & $\begin{array}{l}E T_{A}^{-1-} \\
(n=4)\end{array}$ & $\begin{array}{c}E C E-1^{-/-} \\
(n=13)\end{array}$ & $\begin{array}{l}E T_{A}^{-1-} \\
(n=6)\end{array}$ & $\begin{array}{c}E C E-1^{-/-} \\
(n=7)\end{array}$ & $\begin{array}{l}E T_{A}^{-1-} \\
(n=5)\end{array}$ \\
\hline raa1* & Persistent & 13 & 0 & 0 & 0 & 0 & 0 \\
\hline laa1 & Persistent & 0 & 25 & 8 & 0 & 0 & 0 \\
\hline raa2 & Persistent & 13 & 0 & 15 & 33 & 0 & $20^{\text {Tा }}$ \\
\hline laa2 & Persistent & 0 & 25 & 15 & 33 & $14^{\pi}$ & $40^{\pi}$ \\
\hline \multirow[t]{2}{*}{ raa3 } & Enlarged & 75 & 50 & 46 & 33 & $\mathrm{n} / \mathrm{d} * *$ & $\mathrm{n} / \mathrm{d}$ \\
\hline & Poor cranial extension ${ }^{\S}$ & 0 & 0 & 15 & 50 & 0 & 20 \\
\hline \multirow[t]{2}{*}{ laa3 } & Enlarged & 38 & 0 & 23 & 0 & $\mathrm{n} / \mathrm{d}$ & $\mathrm{n} / \mathrm{d}$ \\
\hline & Poor cranial extension ${ }^{\S}$ & 0 & 0 & 15 & 67 & 0 & 20 \\
\hline raa4 & Regressed & 75 & 50 & 85 & 67 & 71 & 40 \\
\hline laa4 & Regressed & 38 & 0 & 54 & 17 & 57 & 20 \\
\hline raa6 & Persistent & $\mathrm{n} / \mathrm{a}^{\|}$ & $\mathrm{n} / \mathrm{a}$ & 46 & 67 & 29 & 60 \\
\hline laa6 & Regressed & 0 & 0 & 39 & 17 & 14 & 0 \\
\hline $\mathrm{rdc}$ & Persistent & $\mathrm{n} / \mathrm{a}$ & $\mathrm{n} / \mathrm{a}$ & 85 & 100 & 86 & 100 \\
\hline ldc & Persistent & $\mathrm{n} / \mathrm{a}$ & $\mathrm{n} / \mathrm{a}$ & 46 & 83 & 57 & 80 \\
\hline rda & Persistent & $\mathrm{n} / \mathrm{a}$ & $\mathrm{n} / \mathrm{a}$ & 46 & 83 & 86 & 100 \\
\hline lda & Regressed & 0 & 0 & 15 & 0 & 0 & 0 \\
\hline
\end{tabular}

*Abbreviations: $r a a$, right arch artery; laa, left arch artery; $r d c$, right ductus caroticus; $l d c$, left ductus caroticus; $r d a$, right dorsal aorta; $l d a$, left dorsal aorta. ${ }^{\ddagger}$ Abnormalities listed were the most frequently observed in each artery of mutant embryo, and were assessed in comparison to control embryos. None of these abnormalities was observed in wild-type or heterozygous embryos: $n=41$ (E11.5); $n=74($ E12.0-12.5); $n=35$ (E13.0-13.5). ${ }^{\S}$ During arch artery remodeling in wild-type embryos, raa3 and laa3 extend ventrocranially. $\|_{\mathrm{n}} \mathrm{a}$, not applicable, because raa6, rdc, ldc, and rda are normally present in E11.5 wild-type embryos. " Appeared as an extra branching from ascending part of the aortic arch between the left and right common carotid arteries. ${ }^{* *} \mathrm{n} / \mathrm{d}$, not determined, because the cranial extension of arch arteries 3 renders these criteria irrelevant. 
Taken together, the results summarized in Table I illustrate that abnormal regression and persistence were observed during aortic arch development in $E C E-1^{-/-}$and $E T_{A}{ }^{-1-}$ embryos. While subtle differences of defects existed at specific embryonic ages between $E C E-1^{-1-}$ and $E T_{A}{ }^{-1-}$ embryos, a similar overall spectrum of malformations was observed in embryos with both genotypes at E18.5. In the present study, the relatively small number of embryos examined in each stage precludes definitive conclusions as to whether these subtle differences in the occurrence of individual defects are statistically significant between $E C E-1^{-/-}$and $E T_{A}^{-1-}$ embryos. In addition to the defects in patterning of the great vessels, abnormalities of the outflow tract such as abnormal rotation resulting in overriding of aorta, DORV (Fig. 7, $C$ and $D$ ), and PTA (not shown), were observed.

\section{Discussion}

We and Kurihara's group have recently shown that ET-1/ ECE-1/ET $\mathrm{A}_{\mathrm{A}}$-mediated signaling is essential for the normal development of the great vessels and cardiac outflow structures, which depends on the contribution of cardiac neural crest cells $(14,15,20,31)$. In this study, we first examined whether the migration of cardiac neural crest cells was affected in $E C E-1^{-1-}$ or $E T_{A}{ }^{-1-}$ embryos. $E C E-1^{-1-}$ embryos are deficient for the $\mathrm{ET}_{\mathrm{A}}$ ligand, ET-1, due to the lack of local proteolytic process-

\section{E12.0}
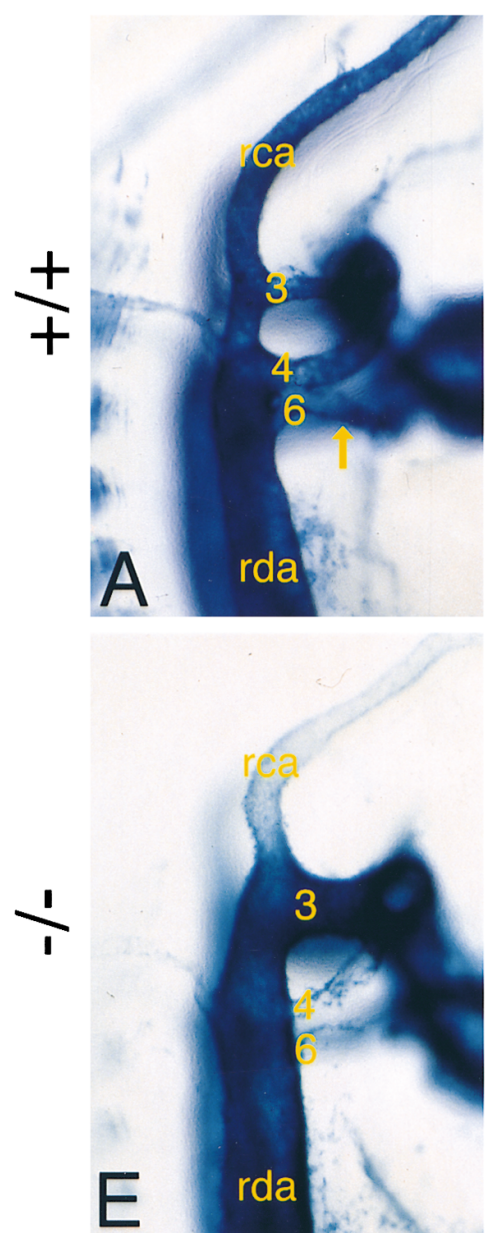
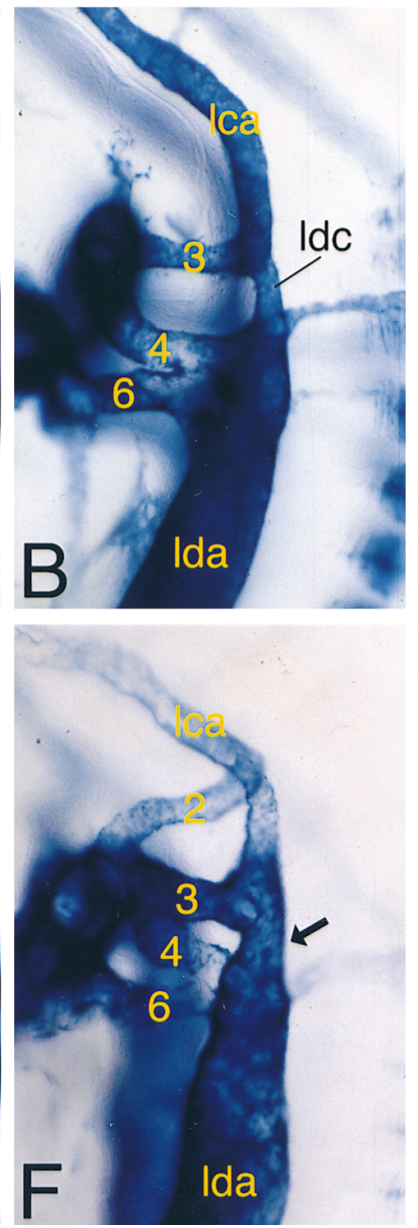
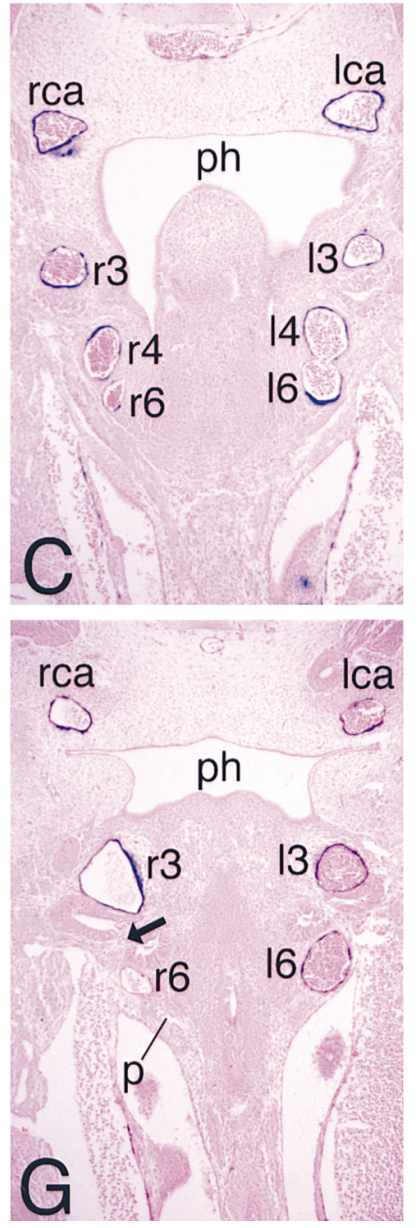
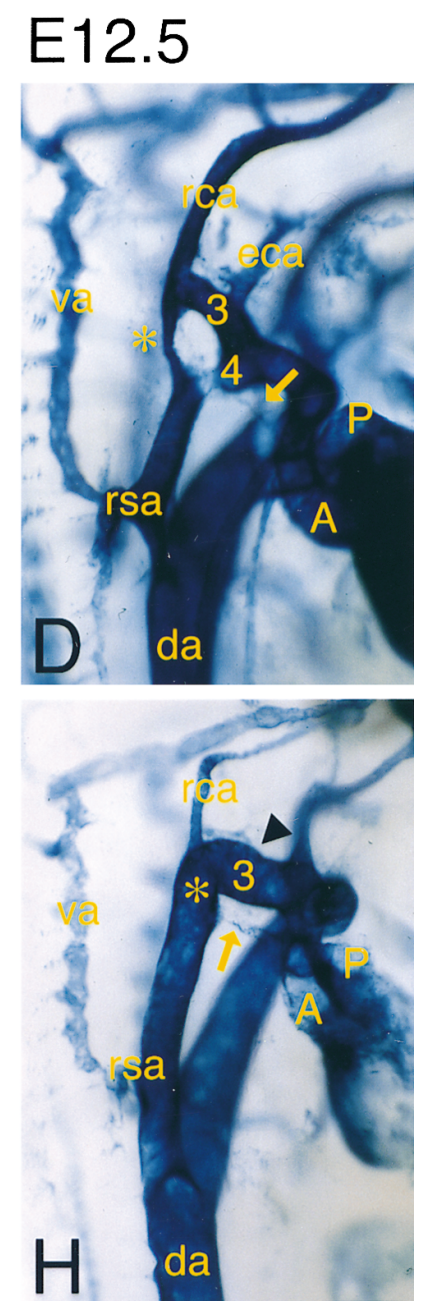

Figure 5. Remodeling of the arch arteries in wild-type $(A-D)$ and $E C E-1^{-1-}$ or $E T_{A}{ }^{-1-}$ mutant $(E-H)$ embryos at E12.0 $(A-C, E-G)$ and E12.5 $(D$ and $H)$, assessed by a wholemount X-gal staining $(A, B, D-F$, and $H)$, and coronal sections stained with hematoxylin and eosin $(C$ and $G)$. $(A)$ Right lateral view of arch arteries. Note that arch artery $6(6)$ starts to narrow at its proximal part (arrow). (B) Left lateral view of arch arteries. Left ductus caroticus $(l d c)$ show narrowing. $(C)$ All the arch arteries and carotid arteries are symmetrical except right arch artery $6(r 6)$ that shows normal narrowing. $(D)$ Right lateral view of arch arteries. Arch artery 3 (3) extends rostrally and arch artery 4 (4) forms the proximal part of right subclavian artery $(r s a)$. Note that narrowing of right ductus caroticus progresses $(*)$ and right arch artery 6 has regressed (arrow) in wildtype embryos. $(E)$ Right arch artery 3 is markedly enlarged and arch arteries 4 and 6 have regressed. $(F)$ Left ductus caroticus does not show normal narrowing (arrow). Note abnormal persistence of left arch artery $2(2)$. (G) Abnormally enlarged right arch artery 3 is seen. Right arch artery 4 is markedly regressed and appears as a remnant (arrow). Left arch artery 4 has disappeared. $(H)$ Abnormally enlarged right arch artery 3 and right ductus caroticus (*) are shown. Right arch artery 4 has abnormally regressed and disappeared whereas right arch artery $6(6)$ has regressed normally (arrow). Note that a branching of external carotid artery seen in a wild-type embryo (eca in $D$ ) is not detected (arrowhead). $r c a$, right carotid artery; $r d a$, right dorsal aorta; $l c a$, left carotid artery; $l d a$, left dorsal aorta; $r 3$, right arch artery; $l 3$, left arch artery; $r 4$, right arch artery; $l 4$, left arch artery; $l 6$, left arch artery; $v a$, vertebral artery; $A$, aortic outflow; $P$, pulmonary outflow; $p$, pulmonary; $p h$, pharynx. 
ing of the inactive intermediate big ET-1 by ECE-1. The timing of migration and amount of migrating cardiac neural crest cells seemed unaffected in $E C E-1^{-/-}$or $E T_{A}^{-1-}$ embryos, judged by the expression of the cardiac neural crest marker CRABP-1. This suggests that, although ET-1/ET $\mathrm{A}_{\mathrm{A}}-$ mediated signaling is not essential for initial migration, it is necessary for the postmigratory development of neural crest cells. In E10.5 wild-type mouse embryos, ET-1 mRNA is expressed in the endothelium of arch arteries and $E T_{A}$ mRNA is expressed in the mesenchyme of the arch arteries, the latter being derived from postmigratory neural crest cells. In addition, ECE-1 mRNA is colocalized both with $E T-1$ and $E T_{A}$ mRNA in the arch arteries. Taken together, ET-1 seems to provide the essential endothelium-derived signals that allow $E T_{A}$-positive neural crest cells to proliferate and/or differentiate in their final environment. Because the expression of $E T_{A}$ mRNA in the arch artery mesenchyme becomes markedly downregulated by E12.0 (our unpublished observation), ET-1 may act at relatively early stages of the postmigratory neural crest development. The role of ET-1 in the development of neural crest cells is clearly distinct from that of pax 3 , which is required for the interaction within/between the neural tube and adjacent tissues to initiate migration of neural crest cells (32).

Our present studies analyzing the $S M 22 \alpha$-lacZ marker transgene expression in $E C E-1^{-1-}$ or $E T_{A}{ }^{-/-}$embryos have revealed several notable features in branchial arch artery development. First, the loss of ET-1/ET $\mathrm{E}_{\mathrm{A}}$-mediated signaling does not affect the initial formation of the branchial arch arteries.
All of the arch arteries are formed in anatomically correct positions at the expected time. This supports the previous findings that neural crest is essential for the persistence rather than initial formation of aortic arteries in neural crest-ablated chick embryos (33). Second, a single gene defect in the endothelin pathway can reproduce the wide spectrum of abnormal aortic arch phenotype in cardiac neural crest-ablated chick embryos (34). This striking diversity of final phenotype is observed even among the $E T_{A}^{-1-}$ embryos with a completely homogenous 129/SvEv genetic background (15) (midgestation embryonic lethality prevents us from examining $E C E-1^{-1-}$ embryos in inbred 129/SvEv background). In addition, the sequential changes of arch arteries including abnormal regression and persistence in specific arch arteries are well documented both in the human congenital anomalies of the aortic arches (35) and in neural crest-ablated chick embryos (36). Third, there is a difference in susceptibility to the loss of ET-1/ET $\mathrm{A}-$ mediated signaling among the six branchial arch arteries. Anterior arch arteries such as arch artery 1 and 2, are less severely affected compared to the posterior arch arteries, and defects manifest mainly as abnormal persistence of the specific vessel. Branchial arch arteries 3, 4, and 6 are most affected in $E C E-1^{-1-}$ or $E T_{A}{ }^{-1-}$ mutant embryos. This is supported by and extends the previous observations that arch arteries 4 were often affected in $E T-1^{-1-}$ embryos (31). Importantly, abnormal regression of arch artery 4 and 6 plays a central role in great vessel malformations in these mutants, such as an absence of the right subclavian artery, interruption of the aortic arch, and formation of
E13.0


Figure 6. Remodeling of the arch arteries in wild-type $(A-C)$ and $E C E-1^{-1-}$ or $E T_{A}{ }^{-1-}$ mutant $(D-F)$ embryos at E13.0. ( $A$ ) Brachiocephalic trunk $(b t)$ and arch artery 3 (3) develop and extend cranially. The connection between right dorsal aorta $(r d a)$ and dorsal aorta $(a r-$ row) is markedly regressed. $(B)$ Arch artery 4 (4) enlarges and forms the segment of the arch of aorta. $(C)$ Left dorsal aorta $(l d a)$ is dominant over right dorsal aorta. The connection between right dorsal aorta and abdominal dorsal aorta narrows (arrow). (D) Right arch artery 4 has disappeared and abnormally persistent right arch artery $6(6)$ is seen. Connection between right dorsal aorta and dorsal aorta persists ( $a r$ row). (E) Left arch artery 3 poorly extends toward cranial direction. Left ductus caroticus $(l d c)$ persists. Note the extra branching near the base of arch artery $3(*)$. (F) Rightsided aortic arch. Left dorsal aorta has regressed (double arrow) and right dorsal aorta has persisted. Left arch artery 6 has regressed (arrow). Right and left arch arteries 4 has disappeared, and right aortic arch 6 is well developed (obstructed from the view). $A$, Aortic outflow; $P$, pulmonary outflow; $r d c$, right ductus caroticus. 
the double aortic arches as well as right-sided aortic arches (see Fig. 8).

What is the cellular mechanism(s) of abnormal regression of branchial arch arteries in $E C E-1^{-1-}$ or $E T_{A}^{-1-}$ embryos? We speculate that mesenchymal cells of the arch arteries, which are derived from $E T_{A}$-positive cardiac neural crest cells, fail to proliferate sufficiently or differentiate correctly in the absence of ET-1/ET - mediated signaling. We cannot rule out the possibility of an increased incidence of apoptosis of the mesenchymal cells, either. This reduction of the mesenchymal mass in arch vessels is also observed in early stages of chick embryos whose neural crest is surgically removed (36). Without mesenchymal support, the arch arteries can no longer maintain blood flow, possibly causing hemodynamic alterations within the arch vessels and conotruncus. These conditions may lead to the further abnormal remodeling of the aortic arches. This is supported by the observations that alteration of intracardiac blood flow can cause defects similar to those observed in neural crest-ablated chick embryos $(37,38)$. It is noteworthy that arch artery 3 never shows abnormal regression in $E C E-1^{-1-}$ and $E T_{A}{ }^{-l-}$ embryos, but rather it shows abnormal enlargement and poor rostral growth. Also, the left ductus caroticus and the right dorsal aorta, which are normally programmed to regress, abnormally persist. These changes may well be secondary to hemodynamic alterations caused by the narrowing of arch arteries 4 and 6 . Vessels that persist have to accept an additional blood flow circumventing the abnormally regressing arches, exposing themselves to constant mechanical and biochemical stimuli, such as sheer stress and growth factors in the circulating blood. As a consequence, their normal regression may be prevented, resulting in a loss of asymmetry in the arterial system. The correct distribution of blood flow through the arch arteries and dorsal aorta seems to be an important factor for the completion of vascular remodeling. Another plausible hypothesis is that ET-1/ET $\mathrm{A}_{\mathrm{A}}$-mediated signaling conveys vasoconstrictive effect on the vessels that are programmed to regress during development. Indeed, ET-1 is known to possess the most potent vasoconstrictive action on the diverse arterial
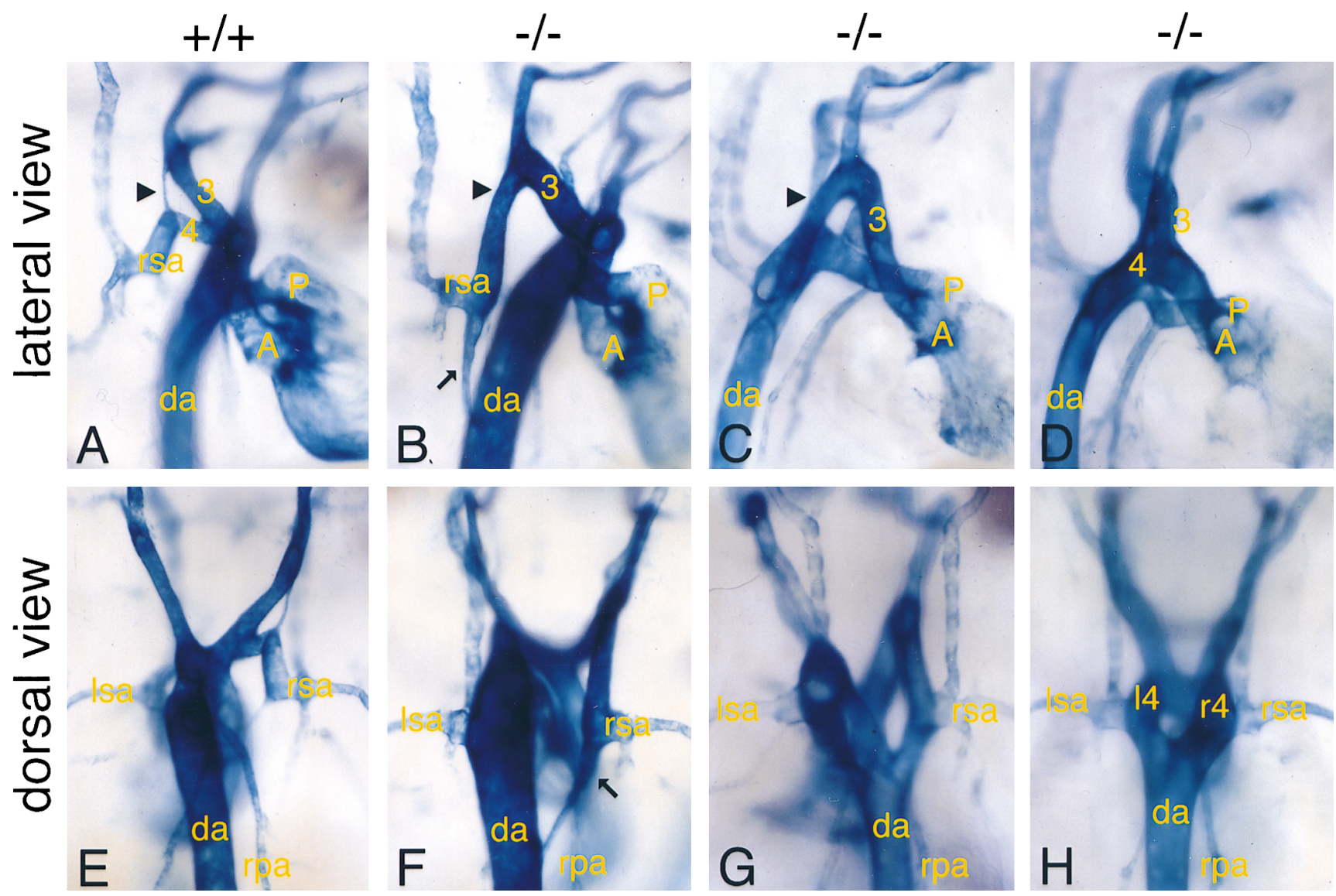

Figure 7. Aortic arch patterning in E13.5 wild-type $(A$ and $E)$ and $E C E-1^{-1-}$ or $E T_{A}^{-l-}$ mutant $(B-D, F-H)$ embryos. Right lateral view $(t o p)$ and dorsal view (bottom) are shown. $(A)$ Right arch artery $3(3)$ becomes common carotid artery and right arch artery 4 (4) forms a proximal part of right subclavian artery $(r s a)$. Note that the right ductus caroticus is regressed in wild-type embryos at this stage (arrowhead). Aortic outflow $(A)$ and pulmonary outflow $(P)$ are separated. $(E)$ Dorsal aorta $(d a)$ is on the left side of the embryo and the connection between right subclavian artery and dorsal aorta has disappeared. (see Fig. $8 A)(B$ and $F$ ) Cervical origin of right subclavian artery. $(B)$ Persistent right ductus caroticus (arrowhead) connects right subclavian artery and right common carotid artery (3). Persistent connection between right subclavian artery and dorsal aorta (arrow) (see Fig. $8 \mathrm{~B}$ ). ( $C$ and $G$ ) Double aortic arches formed by abnormally persistent ductus caroticus (arrowhead) after abnormal regression of arch arteries 4 (see Fig. $8 D$ ). Malrotation of the outflow tract is seen. $(D$ and $H$ ) Double aortic arches formed by bilateral arch arteries 4 after abnormal regression of left aortic arch 6 (see Fig. 8 E). $l 4$, left arch artery 4; lsa, left subclavian artery; $r 4$, right arch artery 4 ; $r p a$, right pulmonary artery. 
vessels (39). Without $\mathrm{ET}-1 / \mathrm{ET}_{\mathrm{A}}-$ mediated signals, these vessels cannot constrict, resulting in abnormal persistence of arch arteries. Another possibility is that ET-1 may affect genes responsible for specifying the identity of the arch arteries along the anterior-posterior axis, similar to Hox genes in branchial arch development $(40,41)$. However, this is less likely because $E T-1$ and $E T_{A}$ expression does not detectably differ among different branchial arch arteries, and Hoxa-2 expression in the branchial arches is not affected in $E T_{A}{ }^{-1-}$ embryos (our unpublished observations). Whatever the exact cellular mechanism(s) for the ET-1/ECE-1/ET $\mathrm{A}_{\mathrm{A}}$ actions are, our failure of detecting a left-right asymmetry in the expression of these molecules in the developing branchial arches and arch arteries suggests that this intercellular signaling pathway functions to create a permissive environment for other factor(s) to act asymmetrically.

Mice deficient for the bHLH transcription factor dHAND, have defects in the initial formation of vessels arising from the heart, resulting in the complete failure of the aortic arch formation (42). Double homozygous mutants for subtypes of RARs, including RAR $\alpha 1$ and $\beta 2$, exhibit similar aortic arch abnormalities to $E T-1^{-1-}, E C E-1^{-1-}$, or $E T_{A}^{-1-}$ embryos (43). They also show conotruncal abnormalities such as PTA and DORV, suggesting that ET-1 and RARs may act in the same genetic pathway in cardiac neural crest development. Mice targeted for activin receptor IIB (44), TGF- $\beta 2$ (45), Hoxa-3 (46), RXR $\alpha$ (47), NF-1 (48), and neurotrophin 3 (49) also show defects in conotruncal regions similar to cardiac neural crestablated chick embryos. These observations suggest that there are multiple signaling pathways involved in the development of conotruncus, parallelly or serially interacting with each other.

In summary, we have shown that postmigratory cardiac neural crest cell development is impaired in $E C E-1^{-1-}$ and $E T_{A}{ }^{-1-}$ embryos, leading to failure of the correct patterning of branchial arch arteries. The primary defect is abnormal regression of specific arch arteries, indicating that $\mathrm{ET}-1 / \mathrm{ET}_{\mathrm{A}}-$ medi-


Figure 8. Schematic representations of aortic arch malformations in $E C E-1^{-1-}$ or $E T_{A}^{-1-}$ mutant embryos. Thick-dotted lines represent abnormal regression; fine-dotted lines show normal regression. Shaded areas depict abnormal persistence. $(A)$ Aortic arch patterning in wild-type embryo. (B) Right subclavian artery of cervical origin caused by abnormal regression of right arch artery 4 and abnormal persistence of right ductus caroticus. $(C)$ Right subclavian artery of dorsal aorta origin caused by abnormal regression of right arch artery 4 and abnormal persistence of right dorsal aorta. $(D)$ Double aortic arches with abnormal persistence of bilateral ductus caroticus caused by abnormal regression of bilateral arch arteries 4. $(E)$ Double aortic arches with bilateral arch arteries 4 caused by abnormal regression of left arch artery 6 and abnormal persistence of right arch artery 6 and right dorsal aorta. $(F)$ Right-sided aortic arch caused by abnormal regression of left dorsal aorta, right and left arch artery 4 , and left arch artery 6 , as well as abnormal persistence of right arch artery 6 , right ductus caroticus, and right dorsal aorta. $r 3$, right arch artery $3 ; l 3$, left arch artery $3 ; r 4$, right arch artery $4 ; l 4$, left arch artery $4 ; r 6$, right arch artery $6 ; l 6$, left arch artery 6 ; $r d c$, right ductus caroticus; $l d c$, left ductus caroticus; $r s a$, right subclavian artery; lsa, left subclavian artery; $r d a$, right dorsal aorta; lda, left dorsal aorta. Drawings are modified from reference 35, with permission granted by W.B. Saunders Co. 
ated signaling is essential for the proper asymmetric maintenance of the mesenchyme of specific arch arteries. Resultant patterns of aortic arch malformations in $E C E-1^{-/-}$or $E T_{A}^{-1-}$ embryos may provide a direct molecular genetic basis for various types of congenital heart and great vessel defects in human neonates.

\section{Acknowledgments}

We thank Li Li and Eric Olson (University of Texas Southwestern Medical Center, Dallas, TX) for the $S M 22 \alpha$-lacZ transgenic mice, Beth Hinnant for technical assistance, Vincent Giguere (McGill University, Montreal, Canada) for the mouse CRABP-1 cDNA, Laure Lecoin (Institut d'Embryologie Cellulaire et Moléculaire du CNRS, Nogent-sur-Marne, France) for helpful discussions, and Cheryl Gariepy (University of Texas Southwestern Medical Center) for critical reading of the manuscript.

M. Yanagisawa is an Investigator, and D.E. Clouthier is an Associate, of the Howard Hughes Medical Institute. This study is supported in part by research grants from the Perot Family Foundation, Excellence in Education Fund, and the W.M. Keck Foundation.

\section{References}

1. Rugh, R. 1990. The mouse. Its reproduction and development. Oxford University Press, Inc., Oxford, UK. 268-272.

2. Kaufman, M.H. 1992. The atlas of mouse development. Academic Press, Inc., San Diego, CA. 63-205.

3. Kirby, M.L., and K.L. Waldo. 1995. Neural crest and cardiovascular patterning. Circ. Res. 77:211-215.

4. Kuratani, S.C., and M.L. Kirby. 1991. Initial migration and distribution of the cardiac neural crest in the avian embryo: an introduction to the concept of the circumpharyngeal crest. Am. J. Anat. 191:215-227.

5. Conway, S.J., D.J. Henderson, and A.J. Copp. 1997. Pax3 is required for cardiac neural crest migration in the mouse: evidence from the splotch $\left(S P^{2 h}\right)$ mutant. Development. 124:505-514.

6. Le Lièvre, C.S., and N.M. Le Douarin. 1975. Mesenchymal derivatives of the neural crest: analysis of chimaeric quail and chick embryos. J. Embryol. Exp. Morphol. 34:125-154.

7. Kirby, M.L., T.F. Gale, and D.E. Stewart. 1983. Neural crest cells contribute to normal aorticopulmonary septation. Science. 220:1059-1061.

8. Nishibatake, M., M.L. Kirby, and L.H.S. Van Mierop. 1987. Pathogenesis of persistent truncus arteriosus and dextroposed aorta in the chick embryo after neural crest ablation. Circulation. 75:255-264.

9. Wilson, D.I., J. Burn, P. Scambler, and J. Goodship. 1993. DiGeorge syndrome: part of CATCH 22. J. Med. Genet. 30:852-856.

10. Van Mierop, L.H.S., and L.M. Kutsche. 1986. Cardiovascular anomalies in DiGeorge syndrome and importance of neural crest as a possible pathogenetic factor. Am J. Cardiol. 58:133-137.

11. Van Mierop, L.H.S., and L.M. Kutsche. 1984. Interruption of the aortic arch and coarctation of the aorta: pathogenetic relations. Am. J. Cardiol. 54: $829-834$

12. Crupi, G., F.J. MacArtney, and R.H. Anderson. 1977. Persistent truncus arteriosus. A study of 66 autopsy cases with special reference to definition and morphogenesis. Am. J. Cardiol. 40:569-578.

13. Cameron, A.H., F. Acerete, M. Quero, and M.C. Castro. 1976. Double outlet right ventricle. Study of 27 cases. Br. Heart J. 38:1124-1132.

14. Yanagisawa, H., M. Yanagisawa, R.P. Kapur, J.A. Richardson, S.C. Williams, D.E. Clouthier, D. de Wit, N. Emoto, and R.E. Hammer. 1998. Dual genetic pathways of endothelin-mediated intercellular signaling revealed by targeted disruption of endothelin converting enzyme-1 gene. Development. 125: $825-836$

15. Clouthier, D.E., K. Hosoda, J.A. Richardson, S.C. Williams, H. Yanagisawa, T. Kuwaki, M. Kumada, R.E. Hammer, and M. Yanagisawa. 1998. Cranial and cardiac neural crest defects in endothelin-A receptor-deficient mice. Development. 125:813-824.

16. Yanagisawa, M., H. Kurihara, S. Kimura, Y. Tomobe, M. Kobayashi, Y. Mitsui, Y. Yazaki, K. Goto, and T. Masaki. 1988. A novel vasoconstrictor peptide produced by vascular endothelial cells. Nature. 332:411-415.

17. Inoue, A., M. Yanagisawa, S. Kimura, Y. Kasuya, T. Miyauchi, K. Goto, and T. Masaki. 1989. The human endothelin family: three structurally and pharmacologically distinct isopeptides predicted by three separate genes. Proc. Natl. Acad. Sci. USA. 86:2863-2867.

18. Xu, D., N. Emoto, A. Giaid, C.A. Slaughter, S. Kaw, D. de Wit, and M. Yanagisawa. 1994. ECE-1: a membrane-bound metalloprotease that catalyzes the proteolytic activation of big endothelin-1. Cell. 78:473-485.

19. Arai, H., S. Hori, I. Aramori, H. Ohkubo, and S. Nakanishi. 1990. Cloning and expression of a cDNA encoding an endothelin receptor. Nature. 348 730-732.

20. Kurihara, Y., H. Kurihara, H. Suzuki, T. Kodama, K. Maemura, R. Nagai, H. Oda, T. Kuwaki, W.-H. Cao, N. Kamada et al. 1994. Elevated blood pressure and craniofacial abnormalities in mice deficient in endothelin-1. $\mathrm{Na}$ ture. 368:703-710.

21. Baynash, A.G., K. Hosoda, A. Giaid, J.A. Richardson, N. Emoto, R.E. Hammer, and M. Yanagisawa. 1994. Interaction of endothelin-3 with endothelin-B receptor is essential for development of epidermal melanocytes and enteric neurons. Cell. 79:1277-1285.

22. Hosoda, K., R.E. Hammer, J.A. Richardson, A.G. Baynash, J.C. Cheung, A. Giaid, and M. Yanagisawa. 1994. Targeted and natural (piebaldlethal) mutations of endothelin-B receptor gene produce megacolon associated with spotted coat color in mice. Cell. 79:1267-1276.

23. Epstein, J.A. 1996. Pax3, neural crest and cardiovascular development. Trends Cardiovasc. Med. 6:255-261.

24. Li, L., J.M. Miano, B. Mercer, and E.N. Olson. 1996. Expression of the SM22 $\alpha$ promoter in transgenic mice provides evidence for distinct transcriptional regulatory programs in vascular and visceral smooth muscle cells. J. Cell Biol. 132:849-859.

25. Hanley, T., and J.P. Merlie. 1991. Transgene detection in unpurified mouse tail DNA by polymerase chain reaction. Biotechniques. 10:56.

26. Giguère, V., S. Lyn, P. Yip, C.-H. Siu, and S. Amin. 1990. Molecular cloning of cDNA encoding a second cellular retinoic acid-binding protein. Proc. Natl. Acad. Sci. USA. 87:6233-6237.

27. Wilkinson, D. 1992. Whole mount in situ hybridisation of vertebrate embryos. In In Situ Hybridisation: A Practical Approach. D. Wilkinson, editor. IRL Press, Oxford, UK. 75-84.

28. Benjamin, I.J., J. Shelton, D.J. Garry, and J.A. Richardson. 1997. Temporospatial expression of the small HSP/ $\alpha$ B-crystallin in cardiac and skeletal muscle during mouse development. Dev. Dyn. 208:75-84.

29. Vecchi, A., C. Garlanda, M.G. Lampugnani, M. Resnati, C. Matteucci, A. Stoppacciaro, H. Schnurch, W. Risau, L. Ruco, A. Mantovani, and E. Dejana. 1994. Monoclonal antibodies specific for endothelial cells of mouse blood vessels. Their application in the identification of adult and embryonic endothelium. Eur. J. Cell Biol. 63:247-254

30. Li, L., J.M. Miano, P. Cserjesi, and E.N. Olson. 1996. SM22 $\alpha$, a marker of adult smooth muscle, is expressed in multiple myogenic lineages during embryogenesis. Circ. Res. 78:188-195

31. Kurihara, Y., H. Kurihara, H. Oda, K. Maemura, R. Nagai, T. Ishikawa, and Y. Yazaki. 1995. Aortic arch malformations and ventricular septal defect in mice deficient in endothelin-1. J. Clin. Invest. 96:293-300.

32. Serbedzija, G.N., and A.P. McMahon. 1997. Analysis of neural crest cell migration in Splotch mice using a neural crest-specific lacZ reporter. Dev. Biol. 185:139-147.

33. Waldo, K.L., D. Kumiski, and M.L. Kirby. 1996. Cardiac neural crest is essential for the persistence rather than the formation of an arch artery. Dev. Dyn. 205:281-292.

34. Bockman, D.E., M.E. Redmond, K. Waldo, H. Davis, and M.L. Kirby. 1987. Effect of neural crest ablation on development of the heart and arch arteries in the chick. Am. J. Anat. 180:332-341.

35. Moore, K.L., and T.V.N. Persaud. 1993. The cardiovascular system. In The Developing Human. Clinically Oriented Embryology. W.B. Saunders, Co., Philadelphia, PA. 304-353.

36. Bockman, D.E., M.E. Redmond, and M.L. Kirby. 1989. Alteration of early vascular development after ablation of cranial neural crest. Anat. Rec. 225:209-217.

37. Hogers, B., M.C. DeRuiter, A.M.J. Baasten, A.C. Gittenberger-de Groot, and R.E. Poelmann. 1995. Intracardiac blood flow patterns related to the yolk sac circulation of the chick embryo. Circ. Res. 76:871-877.

38. Hogers, B., M.C. DeRuiter, A.C. Gittenberger-de Groot, and R.E. Poelmann. 1997. Unilateral vitelline vein ligation alters intracardiac blood flow patterns and morphogenesis in the chick embryo. Circ. Res. 80:473-481.

39. Yanagisawa, M. 1994. The endothelin system: a new target for therapeutic intervention. Circulation. 89:1320-1322.

40. Gendron-Maguire, M., M. Mallo, M. Zhang, and T. Gridley. 1993. Hoxa-2 mutant mice exhibit homeotic transformation of skeletal elements derived from cranial neural crest. Cell. 75:1317-1331.

41. Rijli, F.M., M. Mark, S. Lakkaraju, A. Dierich, P. Dollé, and P. Chambon. 1993. A homeotic transformation is generated in the rostral branchial region of the head by disruption of Hoxa-2, which acts as a selector gene. Cell. 75: 1333-1349.

42. Srivastava, D., T. Thomas, Q. Lin, M.L. Kirby, D. Brown, and E.N. Olson. 1997. Regulation of cardiac mesodermal and neural crest development by the bHLH transcription factor, dHAND. Nat. Genet. 16:154-160.

43. Mendelsohn, C., D. Lohnes, D. Décimo, T. Lufkin, M. LeMeur, P. Chambon, and M. Mark. 1994. Function of the retinoic acid receptors (RARs) during development (II). Multiple abnormalities at various stages of organogenesis in RAR double mutants. Development. 120:2749-2771.

44. Oh, S.P., and E. Li. 1997. The signaling pathway mediated by the type 
IIB activin receptor controls axial patterning and lateral asymmetry in the mouse. Genes Dev. 11:1812-1826.

45. Sanford, L.P., I. Ormsby, A.C. Gittenberger-de Groot, H. Sariola, R. Friedman, G.P. Boivin, E.L. Cardell, and T. Doetschman. 1997. TGFß2 knockout mice have multiple developmental defects that are non-overlapping with other TGF $\beta$ knockout phenotypes. Development. 124:2659-2670.

46. Chisaka, O., and M.R. Capecchi. 1991. Regionally restricted developmental defects resulting from targeted disruption of the mouse homeobox gene hox-1.5. Nature. 350:473-479.

47. Gruber, P.J., S.W. Kubalak, T. Pexieder, H.M. Sucov, R.M. Evans, and K.R. Chien. 1996. RXR $\alpha$ deficiency confers genetic susceptibility for aortic sac, conotruncal, atrioventricular cushion, and ventricular muscle defects in mice. $J$ Clin. Invest. 98:1332-1343.

48. Brannan, C.I., A.S. Perkins, K.S. Vogal, N. Ratner, M.L. Nordlund, S.W. Reid, A.M. Buchberg, N.A. Jenkins, L.F. Parada, and N.G. Copeland. 1994. Targeted disruption of the neurofibromatosis type-1 gene leads to developmental abnormalities in heart and various neural crest-derived tissues. Genes Dev. 8:1019-1029.

49. Donovan, M.J., R. Hahn, L. Tessarollo, and B.L. Hempstead. 1996 Identification of an essential nonneuronal function of neurotrophin 3 in mammalian cardiac development. Nat. Genet. 14:210-213. 